NBER WORKING PAPER SERIES

\title{
THE STABILITY AND GROWTH PACT AS AN IMPEDIMENT TO PRIVATIZING SOCIAL SECURITY
}

\author{
Assaf Razin \\ Efraim Sadka \\ Working Paper 9278 \\ http://www.nber.org/papers/w9278 \\ NATIONAL BUREAU OF ECONOMIC RESEARCH \\ 1050 Massachusetts Avenue \\ Cambridge, MA 02138 \\ October 2002
}

Some of the work on this paper was done while the second author was visiting the economics department atCornell University. We wish to acknowledge the sponsoring RTN project, The Analysis of International Capital Markets: Understanding Europe's Role in the Global Economy. The views expressed herein are those of the authors and do not necessarily reflect the views of the National Bureau of Economic Research.

(C) 2002 by Assaf Razin and Efraim Sadka. All rights reserved. Short sections of text, not to exceed two paragraphs, may be quoted without explicit permission provided that full credit, including (C) notice, is given to the source. 
The Stability and Growth Pact as an Impediment to Privatizing Social Security

Assaf Razin and Efraim Sadka

NBER Working Paper No. 9278

October 2002

JEL No. H0

\begin{abstract}
The aging of the population shakes the confidence in the economic viability of pay-as-you-go social security systems. We demonstrate how in a political-economy framework the shaken cofidence leads to the downsizing of the social security-system, and to the emergence of supplemental individual retirement programs. Lifting the Stability-Pact type ceiling on fiscal deficits is shown to facilitate the transition from a national to a private pension system, through an endogenously determined shift in the median voter.
\end{abstract}

\author{
Assaf Razin \\ Mario Henrique Simonsen Professor of Public Economics \\ Tel-Aviv University \\ Tel-Aviv 69978 \\ ISRAEL \\ and Friedman Professor of International Economics, Cornell University \\ and NBER \\ razin@post.tau.ac.il. \\ Efraim Sadka \\ Henry Kaufman Professor of International Capital Markets \\ Tel-Aviv University \\ Tel-Aviv 69978 \\ ISRAEL \\ sadka@post.tau.ac.il.
}




\section{Introduction}

The economic viability of national old-age security systems has been increasingly deteriorating. Though the recent 2000 population census in the United States reveals some encouraging signs that the ageing process there is checked through increasing fertility rates and migration of young people, the demographic picture for Europe is cloudy. As the Economist puts it:

“As its people grow grayer, Europe's state pensions systems will go deeper into the red. Germany and Italy are trying to push the private-sector alternative. It is not easy..."(August 3rd, 2002, p. 23).

More concretely, for Germany,

"Seven-tenths of German pensions come from a state scheme with roots is Bismarck's day. It is financed mainly by a levy on wages, $19.1 \%$ this year, half paid by workers and half by employers. But, as all over Europe, the demographics are grim. Today, there are 2.8 Germans aged 20 - 59 to support each pensioneer. By 2030 there could be half as many. And the state can’t just fork out money to fill the gap" (op.cit p. 23).

And similarly, in Italy,

"The government's strategy is to get private pension schemes and funds, now embryonic, working properly first. Then, it hopes, it will be politically able to tackle the financing of the pay-as-you-go state system. But Italy cannot afford to wait. Its state's spending on pensions is more than $14 \%$ of GDP, almost double the European Union average. Every year, payouts far exceed contributions by workers and employers" (op.cit. p.24).

Indeed, the aging of the population raises the burden of financing the existing pay-as-yougo national pension (old-age security) systems, because there is a relatively falling number of 
workers that have to bear the cost of paying pensions to a relatively rising number of retirees. Against this backdrop, there arose proposals to privatize social security, as a solution to the economic sustainability of the existing systems. This, by and large, means a shift from the current pay-as-you-go systems to individual retirement accounts (or fully-funded systems). A supposedly added benefit to such a shift is the better return on the contributions to individual accounts than to a pay-as-you-go national pension systems. However, a careful scrutiny of the argument reveals that it is flawed, as neatly demonstrated by Paul Krugman (2002).

Nevertheless, the increased fragility of national pay-as-you-go pension. caused by the ageing of the population, raises doubts among the young about whether the next generations will continue to honor the implicit intergenerational social contract, or the political norm, according to which, "I pay now for the pension benefits of the old, and the next young generation pays for my pension benefits, when I get old". These doubts are, after all, not unfounded, for there will indeed be more pensioneers per each young worker of the next generation, and hence each one of the young workers will have to pay more in order to honor the implicit social contract. With such doubts, the political power balance may indeed shift towards scaling down the pay-as-you-go system, encouraging the establishment of supplemental individual retirement accounts. Such accounts are, by their very nature, fully funded, so that they are not directly affected by the ageing of the population $^{1}$

Naturally, the existing old generation opposes any scaling down of the pay-as-you-go system, because it stands to lose pension benefits (without enjoying the reduction in the social security contributions). This opposition can, however, be softened, or altogether removed, if the

\footnotetext{
${ }^{1}$ Naturally , the aging of the population has some bearing on individual retirement accounts too through its general-equilibrium effects on the return to capital (stemming from the change in the capital-labor ratio).
} 
government creates a budget deficit in order to support the social security system and allow it not to scale down the pension benefits to the current old, so as to fully offset the reduction in social security contributions, or even allow it to maintain these benefits intact. (Of course, this deficit will be carried over to the future, with its debt service smoothed over the next several generations.)

But, here stand in the way the restrictions self-imposed by the European Union in the Stability and Growth Pact which put a ceiling on the current fiscal deficit. ${ }^{2}$ As Guido Tabellini (forthcoming) puts it:

"the current formulation of the Stability and Growth Pact is problematic. The Pact now emphasizes the budget deficit, but neglects the longer term generational imbalances. For instance, consider a pension reform that gradually but permanently reduces pension outlays in the future, but immediately cuts social security contributions, so as to relax political constraints. A transition from a pay-as-you-go towards a fully-funded private pension system could have this effect. Such a reform could run against the Stability Pact as currently formulated, no matter how desirable from an economic point of view."

In this paper we develop an analytical model in which a pay-as-you-go, old-age security system is designed as a political-economy equilibrium. The aging of the population shakes the confidence of the young generation in the viability of the pay-as-you-go system. That is, the aging of the population casts doubts, in the mind of the young generation, whether the national system will be able to continue to pay the same current pension benefits, when they retire. We investigate how

\footnotetext{
${ }^{2}$ The idea of the Stability and Growth Pact is to prevent governments from running loose fiscal policies at the expense of the other euro-area countries. This could happen through either higher interest rates, if the ECB offset the fiscal laxity with tight monetary policy, or by higher risk premium on euro-area government bonds. But, to the extent that the Pact in its current version, is an impediment to social security reform, it can cause the deterioration of the fiscal stance in the future and the social security system will move into deficits.
} 
the fragile viability of the pay-as-you-go system (brought about by aging of the population) can shift the equilibrium towards scaling down this fiscal system (thereby encouraging the emergence of individual retirement accounts). We further examine how lifting the ceiling on fiscal deficits can politically facilitate such a scaling down of pay-as-you-go systems. ${ }^{3}$

The organization of the paper is as follows. Section 2 develops an analytical model of a political-economy design of an old-age social security system. Section 3 explores how the confidence of the young generation affects the size of this system. Section 4 studies how fiscal deficit constraints affect the privatization of social security. Section 5 concludes with empirical implications.

\section{A Political-Economy Design Of Social Security}

Consider a standard overlapping generations model in which each generation lives for two periods: a working period and a retirement period. Following Saint-Paul (1994) and Razin and Sadka (1995), we assume a stylized economy in which there are two types of workers: skilled workers who have high productivity and provide one efficiency unit of labor per unit of labor time, and unskilled workers who provide only $q<1$ efficiency units of labor per unit of labor time. Workers have one unit of labor time during their first period of life, but are born without skills and thus with low productivity. Each worker chooses whether to acquire an education and become a skilled worker, or else remain unskilled. After the working period, individuals retire, with their consumption funded by private savings and social security pension, discussed below.

There is a continuum of individuals, characterized by an innate ability parameter, $e$ which

\footnotetext{
${ }^{3}$ Razin ,Sadka and Swagel (2002) deal with a different issue related to ageing populations. They analyze how the willingless of a falling number of young workers to support an increasing number of retirees is affected.
} 
is the time needed to acquire an education. By investing $e$ units of labor time in education, a worker becomes skilled, after which the remaining $(1-e)$ units of labor time provide an equal amount of effective labor in the balance of the first period. Less capable individuals require more time to become skilled and thus find education more costly in terms of lost income (education is a full-time activity). We assume positive pecuniary costs of acquiring skills, $\gamma$, which is not tax deductible. The cummulative distribution function of innate ability is denoted by $G($.$) with the$ support being the interval $[0,1]$. The density function is denoted by $g=G^{\prime}$.

If an individual with an innate ability level e (henceforth an e individual) acquires skill, then her income is $(1-\tau) w(1-c)-\gamma$, whereas if she remains unskilled her income is $(1-\tau) q w$, where $w$ is the wage rate per efficiency unit of labor and $\tau$ is the social security contribution (tax) rate. Therefore, there exists a cutoff level, $e^{*}$, such that those with education cost parameter below $e^{*}$ will invest in education and become skilled, whereas everyone else remains unskilled. The cutoff level is determined by the equality between the return to education and the cost of education (including lost income):

$$
(1-\tau) w\left(1-e^{*}\right)-\gamma=(1-\tau) q w .
$$

Rearranging terms gives the cutoff level in the education decision:

$$
e^{*}=1-q-\gamma /(1-\tau) w .
$$

To obtain analytical results, we use a specification in which factor prices are not variable. Thus we assume a linear production function in which output, Y, is produced using labor, L, and capital, $\mathrm{K}$ :

$$
Y=w L+(1+r) K .
$$


The wage rate, $w$ and the gross (before depreciation) rental price of capital, $1+r$, are determined by the marginal productivity conditions for factor prices:

$$
w=\partial Y / \partial L \text { and } 1+r=\partial Y / \partial K
$$

These conditions are already substituted into the production function. For simplicity, we assume that capital fully depreciates at the end of the production process. The linearity of the production function can arise as an equilibrium outcome through either international capital mobility or factor price equalization in the presence of goods trade. The two types of labor are assumed to be perfect substitutes in production in terms of efficiency units of labor input.

We assume that the population grows at a rate of $n$. Each individual's labor supply is assumed to be fixed, so that the social security tax does not distort individual labor supply decisions at the margin. The total labor supply does, however, depend on the income tax rate, as this affects the cut-off ability, $e^{*}$, and thus the mix of skilled and unskilled individuals in the economy. In period $t$, the total labor supply is given by:

$$
\begin{aligned}
L_{t} & \left.=\left\{\int_{0}^{e_{t}^{*}}(1-e) d G+q\left[1-G\left(e_{t}^{*}\right)\right]\right]\right\} N_{o}(1+n)^{t} \\
& =\iota\left(e_{t}^{*}\right) N_{0}(1+n)^{t},
\end{aligned}
$$

where $N_{o}(1+n)^{t}$ is the size of the working population in period $t$ (with $N_{o}$ being the number of young individuals in period 0$)$, and $\iota\left(e_{t}^{*}\right)=\int_{0}^{e_{t}^{*}}(1-e) d G+q\left(1-G\left(e_{t}^{*}\right)\right)$ is the average (per worker) labor supply in period $t$. This specification implies that for each $e$ and $t$, the number of individuals in period $t$ with an innate ability parameter less than or equal to $e$ is $(1+n)^{t}$ times 
the number of such individuals in period 0 .

There is a pay-as-you-go, old age social security system by which the taxes collected from the young (working) population are earmarked to finance a pension-benefit to the old (retired) population. Thus, the benefit, $b_{t}$, paid to each individual in period $t$, must satisfy the following pay-as-you-go budget constraint:

$$
b_{t} N_{o}(1+n)^{t-1}=\tau_{t} w L_{t}=\tau_{t} w \iota\left(e_{t}^{*}\right) N_{o}(1+n)^{t}
$$

where $\tau_{t}$ is the social security tax in period $t$. Dividing through by $N_{o}(1+n)^{t-1}$ yields an explicit formula for the pension benefit:

$$
b_{t}=\tau_{t} w l\left(e_{t}^{*}\right)(1+n)
$$

In each period, the benefit of the social-security system accrues only to the old, whereas the burden (the social- security taxes) are borne by the young. Then, one may wonder why would not the young, who outnumber the old in a growing economy, drive the tax and the benefit down to zero in a political-economy equilibrium. We appeal to a sort of an implicit intergenerational social contract which goes like this: 'I, the young, pay now for the pension benefits of the old; and you, the young of the next generation, will pay for my pension benefit, when I grow old and retire". With such a contract in place, the young in period $t$ are willing to politically support a social security tax, $\tau_{t}$, which is earmarked to pay the old in period $t$, a pension benefit of $b_{t}$, because they expect the next young generation in period $t+1$ to honor the implicit social contract and pay them a benefit $b_{t+1}$ which is equal to $b_{t}$, the pension benefit that they actually paid to the old. 
Because factor prices are constant over time, the economy is always at a steady state. We henceforth drop the time subscript $t$. For any social security tax rate, $\tau$, equations (1) and (4) determine the functions $e^{*}=e^{*}(\tau)$ and $b=b(\tau)$. Denote by $W(e, \tau, p)$ the expected lifetime income of a young e-individual:

$$
W(e, \tau, p)=\left\{\begin{array}{c}
(1-\tau) w(1-e)-\gamma+p b(\tau) / 1+r \quad \text { for } e \leq e^{*}(\tau) \\
(1-\tau) w q+p b(\tau) /(1+r) \quad \text { for } e \geq e^{*}(\tau) .
\end{array}\right.
$$

The parameter $p$ is the probability assigned by a young individual to the possibility that the next young generation will indeed honor the implicit intergenerational social contract and pay the pension benefit, $b$, that is paid now to the current old. ${ }^{4}$

In each period, the political economy equilibrium for the social security tax, $\tau$ (and the ensuing pension benefit, $b$ ), is determined by majority voting among the young and old individuals alive in this period. The objective of the old is quite clear: so long as raising the social security tax rate, $\tau$ generates more revenues, and consequently, a higher pension benefit, $b$ they are all for it. The voting of the young is less clearcut. Because a young individual pays a tax bill of $\tau w(1-e)$ or $\tau w q$, depending on her skill level, and receives an expected benefit of $p b /(1+r)$, in present value terms, she must weigh her tax bill against her expected benefit. She votes for raising the tax rate, if $\partial W / \partial \tau>0$, and for lowering it, if $\partial W / \partial \tau<0$. Note that:

$$
\partial^{2} W(e, \tau, p) / \partial e \partial \tau=\left\{\begin{array}{l}
w \text { for } e<e^{*}(\tau) \\
0 \text { for } e>e^{*}(\tau)
\end{array}\right.
$$

\footnotetext{
${ }^{4}$ We assume for simplicity that the indirect utility function (with first and second period consumptions as its arguments are linearly homogenous. Therefore, the indirect utility function is linear in life-time income, implying risk-neutrality. Hence the expected life-time income of a young individual is a relevant indicator of welfare.
} 
Therefore, if $\partial W / \partial \tau>0$ for some $e_{o}$, then $\partial W / \partial \tau>0$ for all $e>e_{o}$; and, similarly, if $\partial W / \partial \tau<0$ for some $e_{o}$, then $\partial W / \partial \tau<0$ for all $\mathrm{e}<e_{0}$. This implies that if an increase in the social security tax rate benefits a particular young (working) individual (because the increased expected pension benefit outweigh the increase in the tax bill) then all young individuals who are less able than her (that is, those who have a higher cost-of-education parameter, $e$ ), must also gain from this tax increase. Similarly, if a social security tax increase hurts a certain young individual (because the increased expected pension benefit does not fully compensate for the tax hike), then it must also hurt all young individuals who are more able than her.

As was already pointed out, the old always opt for a higher social security tax. But as long as $n>0$, the old are outnumbered by the young. To reach an equilibrium, the bottom end of the skill distribution of the young population joins forces with the old to form a pro-tax coalition of $50 \%$ of the population,whereas the top end of the skill distribution of the young population forms a counter anti-tax coalition of equal size. In determining the outcome of majority voting the pivot is a young individual, with an education-cost index denoted by $e_{M}$, such that the young who have an education-cost index below $e_{M}$ (namely, the anti-tax coaliton) form $50 \%$ of the total population. The political-economy equilibrium tax rate maximizes the expected lifetime income of this median voter.

Formally, $e_{M}$ is defined as follows. There are $N_{o}(1+n)^{t} G\left(e_{M}\right)$ young individuals with costof-education parameter $e \leq e_{M}$ (more able than the median voter), and $N_{o}(1+n)^{t}\left[1-G\left(e_{M}\right)\right]$ young individuals with cost-of-education parameter $e \geq e_{M}$ (less able than the median voter). There are also $N_{o}(1+n)^{t-1}$ retired individuals in period $t$ who always join the pro-tax coalition. 
Hence, $e_{M}$ is defined implicitly by:

$$
N_{0}(1+n)^{t} G\left(e_{M}\right)=N_{o}(1+n)^{t}\left[1-G\left(e_{m}\right)\right]+N_{o}(1+n)^{t-1}
$$

Dividing this equation by $N_{o}(1+n)^{t-1}$ and rearranging terms yield the cost-of-education parameter for the median voter:

$$
e_{M}=G^{-1}[(2+n) / 2(1+n)] .
$$

As noted, the political equilibrium tax rate, $\tau$, denoted by $\tau_{o}\left(e_{M}, p\right)$, maximizes the expected lifetime income of the median voter:

$$
\tau_{o}\left(e_{M}, p\right)=\arg \max _{\tau} W\left[e_{M}, \tau, p\right]
$$

The political-economy equilibrium tax rate, $\tau_{o}\left(e_{M}, p\right)$, is implicitly defined by the first-order condition:

$$
\partial W\left[e_{M}, \tau_{o}\left(e_{M}, p\right), p\right] / \partial \tau=B\left[e_{M}, \tau_{o}\left(e_{M}, p\right), p\right]=0,
$$

and the second-order condition is:

$$
\partial^{2} W\left[e_{M}, \tau_{o}\left(e_{M}, p\right), p\right] / \partial \tau^{2}=B_{\tau}\left[e_{M}, \tau_{o}\left(e_{M}, p\right), p\right] \leq 0,
$$

where $B_{\tau}$

is the partial derivative of $B$ with respect to its second derivative. 


\section{The Social Security under Strain: Aging Population}

The aging population puts the pay-as-you-go, old-age social security systems under strain. The burden of financing the pension benefits to the old falls on fewer young shoulders, when population ages, as we have already pointed out. Consequently, the confidence of the young, who currently pay the social security taxes which finance the pension benefits to the old, in the future sustainability of the implicit social contract begins to falter. We capture this drop in confidence by assuming that $p$, the probability, assigned by the young to the possibility that they will receive a pension benefit will remain equal to the pension benefit that they pay now to the old, declines.

In order to find the effect of the survivial probability of the social contract, $p$, on the equilibrium social security tax rate, $\tau_{o}\left(e_{M}, p\right)$, differentiate equation (10) totally with respect to $\mathrm{p}$ to conclude that

$$
\partial \tau_{o}\left(e_{M}, p\right) / \partial p=-B_{p}\left[e_{M}, \tau_{o}\left(e_{M}, p\right), p\right] / B_{\tau}\left[e_{M}, \tau_{o}\left(e_{M}, p\right), p\right]
$$

where $B_{p}$ is the partial derivative of $B$ with respect to its third argument. Because $-B_{\tau}$ is nonnegative [see the second-order condition, equation (10)], it follows that the sign of $\partial \tau_{o} / \partial p$ is the same as the sign of $B_{p}$. It also follows from equation (10) that $B_{p}=\partial^{2} W / \partial p \partial \tau$. Employing equation (5) we find that:

$$
\begin{aligned}
B_{p}\left[e_{M}, \tau_{o}\left(e_{M}, p\right), p\right] & =\partial^{2} W\left[e_{M}, \tau_{o}\left(e_{M}, p\right), p\right] / \partial p \partial \tau \\
& =\left[d b\left[\tau_{o}\left(e_{M}, p\right)\right] / d \tau\right] /(1+r)
\end{aligned}
$$

Naturally, no one will vote for raising the social security tax if $d b / d t<0$, because in such a case when the social security tax is raised the pension-benefit falls. Put it differently, a political- 
economy equilibrium will never be located on the "wrong" side of the Laffer curve, where a tax rate hike lowers revenue. This can also be seen formally. From equation (5), we conclude that

$$
B(e, \tau, p)=\partial W(e, \tau, p) / \partial \tau=\left\{\begin{array}{c}
-w(1-e)+[p /(1+r)] d b(\tau) / d \tau] \text { for } e \leq e^{*}(\tau) \\
-w q+\{p /(1+r)][d b(\tau) / d \tau] \text { for } e \geqq e^{*}(\tau)
\end{array}\right.
$$

Hence, when the lifetime income of the median voter is maximized that is, when $B=0$ [see equation 10], we have

$$
d b\left[\left(\tau_{0}\left(e_{M}, p\right)\right] / d \tau=\left\{\begin{array}{c}
w\left(1-e_{M}\right)(1+r) / p \quad \text { if } e_{M} \leqq e^{*}(\tau) \\
w q(1+r) / p \quad \text { if } e_{M} \geq e^{*}(\tau)
\end{array} .\right.\right.
$$

Thus, it follows from equations $(13)$ and (15), that $B_{p}\left[e_{M}, \tau_{o}\left(e_{M}, p\right), p\right] \geq 0$, and hence, from equation (12), that

$$
\partial \tau_{o}\left(e_{M}, p\right) / \partial p>0
$$

We conclude that in the wake of the aging of the population the confidence of the young population in the future sustainability of the pay-as-you-go ,old-age social security system is shaken, (that is, when $p$ falls). Consequently, the public indeed votes for scaling down the social security system (that is, for lowering $\tau$ and $b$ ). As a result, the young resort to supplemental old-age savings, such as individual retirement accounts. Naturally, the old are worse-off as a result of reducing $b$. But, they are outvoted by the young, whose attitude for lowering $\tau$ has turned intensely stronger, following the reduction in their confidence that they will get the same $b$ that they vote to pay for the current old, when they themselves retire. 


\section{Lifting the Ceiling on Fiscal Deficit}

The old naturally continue to oppose the (partial) transition from a pay-as-you-go, old age social security system to individual retirement accounts, because they lose some of their pension benefits. They also have a strong moral claim that they contributed their fair share to the social security sysytem, when they were young, with the implicit social understanding that they would be entitled to receive pension benefits upon retirement. Their morally justified opposition may be accomodated, in part or in full, if the government can make a debt-financed transfer to the social security sysytem, so as to allow the system to pay pension benefits in excess of the social security tax revenues. This deficit is carried forward to the future, and its debt-service is smoothed over the next few generations, so that its future tax implications for the current young generation is negligible. This, of course, requires some relaxation of any restrictions of the sorts imposed by the Stabilization and Growth Pact in the EU. For simplicity, suppose that the government makes a transfer to the social security system at the amount that is required to keep the pension benefits for the current old intact, despite the reduction in the social security tax rate.

Specifically when $\tau$ falls, then the $b$ in equation (4), that is financed by this $\tau$, falls as well. But, we assume that the government compensates the old generation, so as to maintain the total pension benefits intact. Therefore, despite the fall in $b$, the old are indifferent to the reduction in $\tau$ (and, consequently in $b$ ). Thus, the outcome of the majority voting is effectively determined by the young only. The median voter is now median among the young population only. This median voter has a lower cost-of education index than before, that is, $e_{M}$ falls.

In order to find the effect of a fall in $e_{M}$ on the political-economy equlibrium social security 
tax rate, $\tau_{o}\left(e_{M}, p\right)$, we follow the same procedure as in the preceeding section, and conclude that:

$$
\partial \tau / \partial e_{M}=-B_{e_{M}}\left[e_{M}, \tau_{o}\left(e_{M}, p\right), p\right] / B_{\tau}\left[e_{M}, \tau_{o}\left(e_{M}, p\right), p\right]
$$

where, as before, the sign of $\partial \tau / \partial e_{M}$ is the same as the sign of $B_{e_{M}}$, because $B_{\tau} \leq 0$. Note that $B_{e_{M}}=\partial^{2} W(e, \tau, p) / \partial e_{M} \partial \tau$, [see equation (10). Therefore, it follows from equation (5) that

$$
B_{e_{M}}\left[e_{M}, \tau_{0}\left(e_{M}, p\right), p\right]=\left\{\begin{array}{l}
w \text { for } e_{M}<e^{*}(\tau) \\
0 \text { for } e_{M}>e^{*}(\tau)
\end{array}\right.
$$

Thus, we conclude that $\partial \tau / \partial e_{M}$ is nonnegative: it is positive when the median voter is a skilled individual (that is, when $e_{M}<e^{*}$ ), and zero when the median voter is an unskilled individual (that is, when $e_{M}>e^{*}$ ). Hence, a decline in $e_{M}$ decreases (or leaves intact) the social security $\operatorname{tax} \tau_{o}\left(e_{M}, p\right)$

The rationale for this result is starightforward. All unskilled people have the same expected lifetime income, regardless of their cost-of-education parameter, $e$. Therefore, their attitude towards the $(\tau, b)$ pair is the same for all of them. Hence, the change in the median voter has no consequences on the outcomes of the majority voting when this median voter is an unskilled individual. For skilled individuals, expected lifetime income increases when the education cost parameter, $e$, declines. Because, the social security system is progressive with respect to the cost of education parameter, the net benefit from it (that is the present value of the expected pension benefit minus the social security tax) declines, as expected lifetime income increases (that is, as $e$ falls). Therefore, a decline in the cost-of-education parameter of the median voter, $e_{M}$, lowers the political-economy equilibrium social security tax and pension benefit. 
Thus, relaxing the fiscal constraints of the sorts imposed by the stability and Growth Pact in the European Union may faciliate a (partial) transition from a national pay-as-you-go, old-age social security system to a fully funded private pension system. Such a transition may enhance the sustainability of the national system and boost the confidence in its viability. But this comes at a cost of a lesser degree of redistribution, which is an inherent feature of a national system.

\section{Conclusion}

The idea of the Stability and Growth Pact is to prevent governments from running loose fiscal policies at the expense of the other euro-area countries. This could happen through higher interest rates if the ECB offset the fiscal laxity with tight monetary policy, or through higher risk premium on euro-area government bonds. But the Pact neglects long term fiscal considerations because it creates an impediment to the social-security reforms which can improve the fiscal balance in the future.

We emphasize in the paper that the aging population shakes the confidence in the economic viability of pay-as-you-go, old-age social security systems. We demonstrate how in a politicaleconomy framework this shaken confidence leads to the down-sizing of the social system and the emergence of supplemental individual retirement accounts. Indeed, a study by Razin, Sadka and Swagel (2002) finds a negative correlation between the dependency ratio (which increases with the aging of the population) and labor tax rates in a 1970s-1990s sample that includes twelve Western European countries and the United States. Similarly, a negative correlation was found between the dependency ratio and per capita social tranfers. These findings are consistent with the prediction of the theory that this paper develops, that aging leads to the down-sizing of the 
pay-as-you-go fiscal systems.

\section{References}

Razin, Assaf, Efraim Sadka and Phillip Swagel (2002), "The Aging Population and the Size of the Welfare State", Journal of Political Economy, 110(4), August, pp. 900-918.

Razin, Assaf and Efraim Sadka (1995), "Resisting Migration: Wage Rigidity and Income Distribution", American Economic Review: Papers and Proceedings, May, 312-316.

Saint-Paul, Gilles(1994), "Unemployment, Wage Rigidity and Returns to Education”, European Economic Review, 38(3/4), April, 535-544.

Tabellini, Guido (forthcoming), "Principles of Policy Making in the European Union: An Economic Perspective," CESifo Economic Studies.

Krugman, Paul(2002), "Notes on Social Security", in www.wws.princeton.edu/ pkrugman/. 